\title{
Estrategias y modos de acción en el cruce de prácticas religiosas y coyunturas cotidianas. Una mirada al complejo religioso Ocha-Ifá en la Cuba del Siglo XXI
}

\author{
Javier Rodríguez
}

\author{
Red de Investigadores e Investigadoras Adjuntas, Departamento Ecuménico \\ de Investigaciones, La Habana \\ xavi.antro@gmail.com
}

Licenciado en Ciencias de las Religiones por el Instituto Superior Ecuménico de Ciencias de las Religiones de La Habana, Cuba. Su labor investigativa se inscribe en el dominio de la antropología y la historia comparada de las religiones. En estos campos presta particular atención a las religiones de matriz africana en el contexto cubano, específicamente las prácticas que han sido conceptualizadas por la etnología cubana bajo la categoría complejo religioso Ocha-Ifá. También incursiona en la reflexión epistemológica en torno a estas dos áreas del saber desde una perspectiva construccionista y decolonial. Es investigador- colaborador del Museo Casa de África en Cuba e investigador asociado del Departamento Ecuménico de Investigaciones.

\begin{abstract}
Resumen: El título propuesto para este artículo revela la intención de interrogar la relación existente entre las recomendaciones emanadas de la iniciación ritual en el complejo religioso Ocha-Ifá en Cuba y las prácticas cotidianas. El presente propone analizar algunos de los modos de acción puestos en marcha por los practicantes, a partir de estas recomendaciones, y cómo estos estructuran lo que se ha denominado en este espacio como las relaciones con las diferentes figuras del otro. En este sentido pretende, en primer lugar, mostrar las historias míticas en tanto operadores de estos modos de acción; en segundo lugar, mostrar cómo estas recomendaciones y las acciones que promueven van a dar al traste con la reproducción de prejuicios raciales propios de la sociedad cubana actual: sobre todo una vez que estas recomendaciones entran en contacto tanto con las dinámicas de la vida cotidiana como con las subjetividades e intersubjetividades individuales y colectivas indistintamente.

Palabras clave: Prácticas cotidianas, diferentes figuras del otro, recomendaciones religiosas, complejo religioso Ocha-Ifá, modos de acción.
\end{abstract}

Cuadernos de Antropología 2014, 24(1), 3-20

Recibido: 25-02-2014 / Aceptado: 10-06-2014

Revista del Laboratorio de Etnología María Eugenia Bozzoli Vargas

Escuela de Antropología, Universidad de Costa Rica

http://revistas.ucr.ac.cr/index.php/antropologia

ISSN 2215-356X

c) (i) Cuadernos de Antropología está bajo una licencia Creative Commons Attribution-NonCommercial-ShareAlike 3.0 


\begin{abstract}
The proposed title for this article reveals the intention to examine the relationship between the recommendations emanating from the religious ritual initiation on the complex Ocha-Ifá in Cuba and its daily practices. This article aims to analyze some of the modes of action launched by practitioners from these recommendations and how they structure what has been referred to in this space as relations with the different figures of the other. In this sense, it intends, first, to show the mythical stories as operators of these modes of actions, secondly, to show how these recommendations and promoted actions will end racial prejudices found in contemporary Cuban society: especially once these recommendations come in contact both with the dynamics of everyday life such as the individual and collective subjectivities and intersubjectivities interchangeably.

Keywords: Daily practices, different figures of other, religious recommendations, Ocha-Ifá, modes of action.
\end{abstract}

\title{
Introducción
}

No pasan desapercibidas, incluso para el observador menos interesado, las prácticas religiosas de matriz africano en el contexto cubano. En las calles de La Habana, entre lo lúgubre de los edificios, las calles con sus desmanes estructurales, los comercios estatales y particulares, la música a altos volúmenes, los ruidos, los anuncios, la diversa masa de individuos camina o se apresura para alcanzar el transporte, hace sus filas para comprar algún producto, busca las diferentes oportunidades para solventar necesidades familiares o personales; otras veces se detiene ante la disyuntiva o algún cansancio producto del ajetreo diario, pero siempre vuelve a emprender nuevas marchas insertada en una realidad que parece escaparse de un socialismo soñado. Y cuando se habla de diversidad o "lo diverso", la imagen a no perder de vista es precisamente la de un espacio donde convergen una multiplicidad de identidades dialogantes: el cristiano marxista, el ateo, el revolucionario agnóstico, el obrero, el retirado, el musulmán cubano y los practicantes de las religiones cubano-africanas. Estos últimos -específicamente los inscritos en las lógicas míticorituales del complejo religioso Ocha-Ifá- se destacan por portar en sus cuerpos los atributos de sus orichas: collares, pulseras, atuendos de colores y figuras específicas; es decir, todo lo que de identitario tienen estos elementos para su rápido reconocimiento.

Este complejo religioso, conformado por los segmentos Ocha e Ifá, codependientes y complementarios uno de otro, se inscribe en esa amplia gama de creencias y prácticas religiosas provenientes de África, que la etnología cubana ha observado como legado cultural transmitido y adecuado al Nuevo Mundo por los actores de la trata negrera alrededor de la segunda mitad del siglo XIX y cuyos límites se desdibujan, sobre todo al estar fundados, ambos, según Menéndez (2002, p. 21) en "el culto al par de egun-oricha y el respeto a los sistemas predictivos-interpretativo tradicionalmente denominados sistemas adivinatorios". Egun (los antepasados o la ancestralidad) y Orichas: entidades sobrenaturales encarnadas en los fenómenos de la naturaleza (el rayo, el río, el mar, la centella, etc.), pero también humanizados o antropomorfizados, pues se les atribuyen virtudes y defectos, carácter, tramas emocionales, vivencias, historias de vida, 
saberes, conflictos de poder, etc. propios de hombres y mujeres comunes; desempeñan un rol determinante, pues a través de los métodos de adivinación (forma de comunicación de Orichas y Egun con el practicante) pondrán en perspectiva la resolución de las problemáticas concernientes a la vida humana.

Estos elementos señalados como modelos de identidad y conjuntamente con ellos, los rituales pertinentes antes de su obtención y uso, vienen a simbolizar indistintamente (sea en el segmento referido a Ocha o al segmento Ifá) un "compromiso religioso" de gran importancia (con mayor o menor implicaciones según la jerarquía ritual del practicante) una vez que comienza la participación activa en estos cultos. En esta misma línea, es posible constatar que el resultado de estos rituales representa -al decir de los practicantes- una suerte de "carné de identidad religioso". Un aspecto destacable en este sentido es que si bien aquí se define una serie de elementos que pueden ser asumidos como identitarios, los resultados de estos rituales, más allá de lo anterior, pretenden avizorar también sobre otras cuestiones más mediatas a la existencia (formas en que los individuos están y se manifiestan en el mundo). Estas serían las concernientes, principalmente, a las diferentes problemáticas que se presentan o puedan presentarse a la individualidad humana, sus dinámicas de cambio, sus normalizaciones u orientaciones para el desarrollo "armónico" de la vida. Las lógicas que subyacen a estos procesos, la especificidad que lo hace procurador de una "normalización" de la vida ante determinados eventos o hechos de lo cotidiano, remiten directamente a comentar, de forma general y para los dos segmentos adscritos a este complejo religioso, sobre los resultados de una ceremonia ritual que se realiza en el proceso de iniciación: lo que esta tradición religiosa en Cuba ha denominado como día de Itá o Itá.

El término Itá, cuyo significado es mitos (itan en lengua yoruba) según De Sousa (2005) y la ceremonia en sí, es traducido por algunos practicantes como "consejos" o "sentencias", pues en esta se darán informaciones o recomendaciones de carácter vital para el individuo iniciado. En esta dinámica pudiera expresarse que su realización es de trascendental significación para el adepto, ya que tiene como finalidad normar su vida a partir de ese momento (Menéndez, 1998). Aquí, mediante los medios o métodos de adivinación utilizados en cada segmento (el dilogun para el segmento Ocha y las semillas -Ikin- para el segmento Ifá) se determinan las problemáticas que afronta el practicante al momento de iniciarse y las que confrontará luego en su vida cotidiana. Estas problemáticas, los augurios del oricha para el practicante, todo su plan terrenal vienen marcados por los odun revelados por los métodos de adivinación. Estos odun, también llamados signos, letra, son marcas hechas en el polvo de adivinación utilizado en el segmento Ifá para esta actividad ${ }^{1}$ o las figuras formadas a partir de las diferentes posiciones de los caracoles una vez que son arrojados en

\footnotetext{
1 La obtención de estos odun se produce al golpear -el sacerdote de Ifá- dieciséis semillas (ikin: representación material de Ifá) y marcar en el polvo (iyerosun) disperso en el tablero (opon) consagrado para esta actividad dos líneas paralelas y verticales formadas a su vez por cuatro líneas discontinuas. En dependencia de cuántas semillas queden en la mano izquierda del oficiante (una o dos), cada una de estas marcas discontinuas se duplica. Esta actividad se realiza tres veces con el propósito de obtener los tres odun que van a ser utilizados para la lectura del Itá.
}

Cuadernos de Antropología 2014, 24(1), 3-20 
una estera, tal como se hace en el segmento Ocha (dilogun $)^{2}$. Esta noción (odun) puede conceptualizarse como la figura o espacio simbólico donde está depositado el saber ancestral acumulado, las historias que llevan implícitas una enseñanza; las recomendaciones; los suyeres o rezos, las dolencias que padece o puede padecer el consultante; su vida privada y pública, los orichas que "hablan" por esa letra u odun y los ebo (ceremonia de ofrenda, de sacrificio o de purificación) que debe ofrecer el practicante para mejorar cualquier situación desfavorable o procurar la llegada de una mejor. En cualquier caso, odun será entonces el lugar donde está contenido toda la información concerniente a la vida en sus tres dimensiones: pasado, presente y futuro; el saber que permitirá al practicante desenvolverse en su cotidianidad. Por tanto cada odun se presenta como procurador de un saber intemporal, ancestral, cíclico, siempre en consonancia con la vida y volcado a dar continuamente razones de las diferentes vicisitudes o bienaventuranzas implícitas en ella (la vida) ${ }^{3}$. En referencia a lo anterior, la etnología precisa ${ }^{4}$ que en este día se hablará u orientará al practicante sobre:

Las precauciones con relación a todo lo que resulte pernicioso a su molde tipificado de individualidad, las orientaciones sobre los requerimientos necesarios de su régimen alimenticio, el esclarecimiento de la conducta a asumir frente a determinadas situaciones y personas, los colores y formas de la vestimenta, (...) la conducta adecuada en evitación de las frustraciones personales, (...) las facultades o aptitudes innatas para la mejor realización en su perfil profesional, (...) las tendencias al padecimiento de ciertas patologías propias de su individualidad" (Aboy, 2004, p. 5).

2 Los caracoles lanzados encima de una estera son dieciséis. En dependencia de la caída de estos se forma el odun.

3 Estos odun están contenidos en dos espacios. El primero, una compilación escrita de un complejo corpus que reúne todo un conjunto de conocimientos acumulados en el devenir histórico-social cubano; aun cuando este se haya separado de la cosmovisión que lo produjo por cuestiones o problemáticas concernientes a su transmisión oral. O sea, este corpus se ha conformado a partir de una realidad diferente, cambiante; perdiendo y ganando elementos que han configurado los saberes aprehendidos en la experiencia de trabajo de los oficiantes del culto y que han quedado plasmados en los libros que circulan en los herbolarios o casas donde se comercializan artículos religiosos vinculados con estos tipos de prácticas. Un elemento importante a tener en cuenta es que la confrontación constante entre las experiencias adquiridas en el trabajo cotidiano y la puesta de estos saberes en una suerte de "canon" abierto es lo que ha mantenido un corpus vivo, siempre presto a experimentar nuevas transformaciones. El segundo espacio de donde se erigen estos saberes es precisamente una forma de oralidad inscrita en los marcos del ejercicio de la práctica y que desborda el propio "canon" a medida que se van incorporando elementos asociados a su ejercicio o a cambios en la geografía sociocultural. Esta "nueva forma de oralidad” es la que permite afirmar una naturaleza abierta y dinámica en materia de circulación de saberes, dando lugar a un canon abierto.

4A modo general, ambos segmentos transitan por estas recomendaciones, aunque se debe agregar que en cada uno de ellos se hace mayor énfasis en algunos aspectos que en otros. Esto ocurre no en detrimento de algunos de ellos, sino valorando su relevancia para el individuo iniciado y de acuerdo su molde individual.

\section{http://revistas.ucr.ac.cr/index.php/antropologia}


Se detallan, también, los sacrificios o ceremonias adicionales que realiza el individuo iniciado, que deberían llevarse a cabo lo antes posible para que los aspectos positivos emanados del proceso de iniciación emerjan y los aspectos negativos se disipen lo más rápidamente posible.

Estas precauciones o recomendaciones ${ }^{5}$ se erigen, entonces, como reguladoras de la amplia gama de acciones que pueden manifestar los practicantes en su quehacer cotidiano. Son las detentoras de un mayor alcance operativo en la vida de estos, pues pondrán en perspectiva, desde ese mismo instante, una serie de problemáticas que puede surgir en los espacios privados: el hogar, la familia, etc., o en los espacios públicos de estos: aquellos lugares donde se produce el ajetreo cotidiano o las luchas por la sobrevivencia ${ }^{6}$. En este sentido, convocan a poner en funcionamiento - luego de complejos procesos de internalización y externalización de sus contenidos- un repertorio de acciones cuyo propósito principal será inscribir a los practicantes en un mundo ordenado; insertarlos, si se quiere, en una "realidad vigilada" y "organizada" que permita el desarrollo armónico de la existencia. Estos elementos, aunque sucintos, llamaron a cuestionar sobre: ¿cuáles serían, entonces, las relaciones entre estas recomendaciones y las prácticas cotidianas? La pregunta en sí misma condujo a analizar algunos de los modos de acción puestos en marcha por los practicantes a partir de las recomendaciones emanadas de la iniciación ritual en el complejo religioso Ocha-Ifá, y cómo estos modos de acción desde su dimensión estratégica van a estructurar lo que se ha definido en este espacio como las relacionas con las diferentes figuras del otro; donde ese otro se muestra en las interacciones cara a cara (Berger y Luckmann, 2011) o en situaciones de co-presencia (Giddens, 2006). Ubicar estos modos de acción como eje central a la hora de abordar estas prácticas religiosas está determinado por un hecho factual que pudo comprobarse una vez efectuado el primer acercamiento tanto a la práctica religiosa como a los individuos adscritos a ella. Se trata precisamente de que más allá de que el énfasis de estas recomendaciones devenga en el dominio y control de la existencia individual concreta $\mathrm{y}$, por consecuencia, en las subjetividades individuales como sugiere la lógica ritual, el practicante iniciado no pierde de vista su libertad en lo tocante a los usos estratégicos o instrumentalizaciones de estas recomendaciones al interior de las complejas dinámicas de la vida cotidiana. Existe, en este sentido, un margen de movilidad ante el carácter "normativo" de la práctica religiosa que el practicante iniciado le

5 Parece pertinente aclarar que estas recomendaciones no son “(...) una relación de preceptos y observancias que se conozcan de antemano y que regulen una vida ejemplar en un contexto social, tampoco es resultado del criterio personal de un grupo de sacerdotes, a los que el iniciado se debe someter; luego el código de observancias de un iniciado, no es por tanto, el motivo de su iniciación; tampoco es una convicción o conversión a un credo que se asuma por convencionalismos sociales y contribuyan a proporcionar, un estado de opinión favorable en un consenso de la sociedad; tampoco es en modo alguno un crédito o un curriculum sacrosocial; sino que por el contrario resulta ser una consecuencia del proceso iniciático y por ende, no solo se desconoce, sino que simplemente, no existe hasta tanto el individuo no se inicie en el culto" (Aboy, 2004, pp. 3-4). Es válido acotar, además que estas recomendaciones pasan por la subjetividad, el sesgo cultural, la habilidad para interpretar los Odun del sacerdote de Ifá en el segmento Ifá o el Obba u Oriaté en el segmento Ocha.

6 Sobre todo porque la historia ha querido que estas prácticas sean percibidas como zona de resistencias ante determinadas desestructuraciones sociales, económicas, políticas, etc.

Cuadernos de Antropología 2014, 24(1), 3-20 
atribuye y que es aprovechado por este una vez que se reinserta en su vida cotidiana; una movilidad que puede pensarse desde la dinámica de estos modos de acción evocados cuya naturaleza ilimitada pone en perspectiva la creatividad humana frente a situaciones límites o de confrontación con la dureza del mundo.

La intencionalidad de observar esta práctica cotidiana -en sus múltiples formas y atravesada por el elemento religioso-, por otro lado, responde al remarcado individualismo emergente en la sociedad cubana actual (Hernández, 2009). Un individualismo que es el producto de una crisis de valores severa y explicita donde la realidad de cada cual importa más que la realidad grupal, donde las carreras o las luchas por la obtención de ciertas garantías y cierto bienestar se fomenta a expensas del otro sin importar sus consecuencias. Una realidad donde contantes cambios en los niveles económicos, políticos y sociales complejizan las dinámicas sociales creando asimetrías y descontentos, configurando nuevas clases sociales y promoviendo con ello, otros modelos de relación ${ }^{7}$. Sería interés, por tanto, analizar de forma crítica estos modelos "otros", sobre todo porque pueden poner en la palestra viejas formas de exclusión y prejuicios sociales, así como también reflejar una cotidianidad marcada por la desconfianza, el riesgo, la incertidumbre (el otro más cercano puede ser el "enemigo") típica de una situación que reclama para describirla el uso de viejos dichos típicos de la sabiduría popular cubana como "sálvese quien pueda" o "aquí lo que no hay es que morirse". El artículo se divide en cuatro secciones. La primera I- Teóricas de partida, aquí se exponen las nociones utilizadas como referentes y se comenta sobre la metodología para la obtención de los datos etnográficos (historias de vidas): I.1- De los modos de acción, I.2- Apuntes sobre la historia de vida. La segunda y tercera sección están volcadas a exponer y analizar dos de las historias de vida recogidas en el trabajo de campo: II- Ifalawo, patakin: operador mítico-simbólico; III- Obiní, (con) vivencias... La cuarta y última sección, IV-Consideraciones finales, ofrecen algunas conclusiones a partir de los análisis realizados.

\section{Teóricas de partida}

\section{De los modos de acción}

Elegir un punto de partida para intentar construir teorías alrededor de las prácticas religiosas de ascendente africano en Cuba constituye un reto para cualquier investigador. De igual modo, asumir las complejidades y dinámicas que encierran la práctica en cuestión, así como el libre accionar humano, las permisibilidades del propio ejercicio religioso, se presentan como una tarea compleja y delicada. Atendiendo a ello se escoge como punto de partida uno de los aspectos más controversiales o de difícil tra-

7 Es curioso que un tema tan polémico como este no haya sido cabalmente abordado desde la academia u otra instancia de investigación en Cuba. Muy pocos investigadores toman en cuenta este fenómeno y cuando lo hacen es perceptible una postura no muy crítica al respecto, pues logran ubicar categóricamente estas problemáticas en lo externo (capitalismo, bloqueo económico, etc.) y no toman en cuenta los factores internos que han vehiculizado este fenómeno en Cuba. Lo cierto es que los artículos son aislados y en muchos casos no circulan o no están siendo socializados de forma eficiente. 
tamiento en lo referente a esta práctica religiosa: esto que ha quedado enunciado antes como los modos de acción implementados por los practicantes a partir de las recomendaciones emanadas de la iniciación ritual. Situar estos modos de acción como punto de partida equivale a concientizar las diferentes gradaciones que adopta la implementación de las recomendaciones en la vida cotidiana ${ }^{8} \mathrm{y}$, por tanto, asumir su no consentimiento en la praxis -al menos desde una perspectiva ideal- ${ }^{9}$. No obstante, lo que interesa destacar sobre este asunto -y por ello su inclusión en este marco- es que la puesta en marcha de estos modos de acción pueden mostrar no solo, cómo ciertas coyunturas económicas, sociales, culturales, vivenciales se presentan como favorables o desfavorables en aras de implementar estas recomendaciones, sino cómo estas mismas circunstancias en combinación con esa "ratio popular" tributaria de cierto arte de utilizar (supeditado a la astucia y a la invención humana) "solucionan" las problemáticas o tensiones individuales aparejadas a las diferentes dinámicas sociales y, al mismo tiempo, los niveles de obediencia exigidos por la iniciación en la práctica religiosa. Poner en perspectiva estos modos de acción y las estrategias que ellos suponen, por otro lado, parte de pensar los efectos emancipatorios que estos modos de acción suponen frente a determinadas coyunturas cotidianas. Y cuando se habla de emancipación, la idea a manejar aquí está ligada a las complejas situaciones propias de la vida cotidiana, a una emancipación que involucra a la vida de cubanos y cubanas en el diario vivir, al cubano de a pie. Hablar de emancipación, con sus conflictos y matices (aspectos que van a asumir un rol particular en este artículo), es explicitar las posturas de los practicantes frente a determinadas catástrofes biográficas, e involucra, al mismo tiempo, sus posturas y actos subvertidores frente a ellas, sus voluntades de cambio, reflejo directo de verdaderas inconformidades o descontentos ante coyunturas existenciales de difícil manejo.

Pensar estos modos de acción parte de adscribir lo anterior (no sin ciertos acomodos coyunturales) a la apuesta metodológica que Michel De Certeau hace en su libro La invención de lo cotidiano (2000) cuyos objetivos son: explicitar las combinatorias operativas que componen una cultura y exhumar, desde aquí, modelos de acción a partir de determinados consumos culturales impuestos por las estructuras dominantes, o lo que el mismo autor denomina, frente a una idea errónea de pasividad en lo

$8 \mathrm{Si}$ se le define negativamente, aun cuando las Ciencias Sociales no se contenten con ello, la vida cotidiana no consiste ni en la vida del trabajo, ni en las luchas por la sobrevivencia o contra la dureza del mundo, no está determinada por los conflictos aparejados a la existencia, por la vida familiar con su entorno y sus relaciones funcionales o disfuncionales, tampoco, por el ocio. No se refiere únicamente a las rutinas y acontecimientos diarios, tampoco consiste en las prácticas mismas que enriquecen y sustentan toda la vida cotidiana. No consiste en sus relaciones esenciales con los bienes y los otros, sus ritmos, a través de los cuales le es posible pasar de una actividad delimitada a otra totalmente distinta (Lefébvre, 1978). Sin embargo, es todo esto; la vida del ser humano que va de lo uno a lo otro, siempre adicionando o restando eventos: afortunados o desafortunados; contextos favorables o desfavorables, expectativas, situaciones extraordinarias, percepciones, sentimientos, acontecimientos y rutinas. En esta lógica, la vida cotidiana se constituye a partir de los encadenamientos y los conjuntos que la integran y que permiten su repetición: "Lo cotidiano son los actos diarios pero sobre todo el hecho de que se encadenan formando un todo" (Lefébvre, 1978). Un todo que sintetiza la vida social, cultural, política, económica e histórica de una nación.

9 Es notable que, en su dimensión práctica, estas formas de religiosidad asuman y negocien en su relación con lo cotidiano, las formas de aplicación e interpretación de mitos, ceremonias, normas de conducta, objetos y artículos destinados a estos ceremoniales, etc. 
concerniente a estos consumos: maneras de hacer, esquemas de acción, maneras de emplear o combinaciones operatorias llevadas a cabo por los individuos en tanto libres de elegir, manipular, transformar tales productos a conveniencia.

Se trata, entonces, de analizar los comportamientos. Sobre todo al tener en cuenta que evocarlos y asumirlos como modos de acción, conjuntamente con las consiguientes estrategias que ellos entrañan, supone pensar el trabajo artesanal de los practicantes con respecto a la autoridad propuesta por el culto; específicamente por estas recomendaciones emanadas del ejercicio religioso en su contacto con los contextos vivenciales de los practicantes. Un trabajo cuyo objetivo es transformarlas y utilizarlas estratégicamente de acuerdo con las necesidades y reglas propias de sus respectivas individualidades. Y aquí llamo estrategias al cálculo de relaciones de fuerza que se vuelve posible a partir del momento en que los practicantes, envestidos con una voluntad y un poder que le son propios, se adscriben o se aíslan del ambiente cifrado por el control ritual y social buscando un espacio de acción susceptible de circunscribirse como su lugar propio; un lugar que luego sirve de base para el manejo de sus relaciones con la exterioridad: por un lado, la propia cuestión "normativa" y "reguladora" de la práctica religiosa y, por otro, el contexto vivencial, social, cultural, económico y político en el que se desarrollan sus vidas y sus prácticas. El uso del término estrategia viene a justificarse en este espacio por el hecho de que las prácticas dan una respuesta adecuada ante la coyuntura. Las estrategias, "mañas" sutiles, navegan entre las reglas, ponen en juego todas las posibilidades ofrecidas por las tradiciones, utilizan esta mejor que aquella, compensan esta con aquella. Sacan provecho de lo suave que oculta lo duro, crean en este medio sus propias pertinencias (De Certeau, 2000). El propio Pierre Bourdieu (2007) reconoce en ellas (las estrategias), en tanto punto intermedio entre las estructuras sociales objetivas y las coyunturas, algunos procedimientos esenciales que vale la pena acotar: a) la polivalencia: la misma cosa tiene empleos y propiedades que varían según las combinaciones en las que entra a formar parte; b) la sustituibilidad: una cosa siempre puede ser remplazada por otra, debido a la afinidad de cada una con las demás en la totalidad que representa; c) la eufemización: hay que ocultar el hecho de que las acciones contravienen las dicotomías y antinomias representadas por el sistema de símbolos.

\section{Apuntes sobre la historia de vida}

Según González y Villegas (2009), la selección de un método de investigación no es un asunto meramente técnico; este ha de estar coherentemente sintonizado con el problema que está siendo estudiado y es este el que lo define; así que cada problema de investigación reclama y exige su propio método específico de abordaje; por tanto, no hay un "método único" susceptible de ser aplicado, sino que cada caso de estudio en concreto requiere de la construcción de un método particular. Con base en estas ideas, se propone entonces un estudio de corte etnográfico exploratorio cuyo punto de anclaje se encuentra en la construcción y/o recreación de las historias de vida de los practicantes incluidos en la muestra.

http://revistas.ucr.ac.cr/index.php/antropologia 
Muy utilizada en estudios sobre vida cotidiana la historia de vida consiste, en el análisis y transcripción que efectúa un investigador del relato que realiza un individuo sobre los acontecimientos y vivencias de su propia vida. Este análisis supone todo un proceso de indagación sobre las maneras de entender, comprehender, experimentar e interactuar con el mundo y su realidad; de esta última intentando siempre conferir al relato de vida cotidiana o a algunos aspectos específicos de esta, cierta unidad holística. Lo que se intenta con esta forma de historiar es precisamente poner al descubierto no solo los aspectos de una cotidianidad individual, sino presentar los eventos sociales, culturales, económicos, políticos significativos que marcan esa cotidianidad. La construcción de historias de vida implica también abordar las percepciones que el propio practicante tiene acerca de sus acciones y experiencias en tanto individuo semiautónomo y social. Unido a ello, explicitar los elementos subjetivos que a manera de telón de fondo recorre y ayuda a conformar el espacio cotidiano individual a través de las interpretaciones, percepciones que él mismo tiene de sus prácticas y del mundo. Como apuntan Gonzáles y Villegas (2009), la trascendencia hacia lo social que tiene la historia de vida individual es un elemento importante, puesto que permite desentrañar la relación entre el tiempo biográfico y el tiempo histórico.

Hacer historia de vida proporciona conocimientos que favorecen la comprensión de las situaciones socio-afectivas, políticas y económicas que han caracterizado la vida de un individuo, que ha sido un reflejo de la sociedad de la cual ha formado y forma parte. Con miras a reconstruir estas historias de vida se utilizaron como técnica, dos tipos de entrevistas: entrevistas dialógicas y entrevistas en profundidad. La combinación de estas procuró acceder al arsenal de ideas, percepciones, contextos socio-históricos que han dado lugar a los modos de acción puestos en marcha por los practicantes en relación con la práctica interrogada. La intención principal es poder traducir en el propio lenguaje del practicante sus experiencias y percepciones, sus acciones y las lógicas que las movilizan; exponer esa gramática de la creatividad, la invención o el reacomodo estratégico que ellos desde su lugar privilegiado hacen de las recomendaciones.

La selección de las dos historias de vida que serán tratadas a continuación no es arbitraria. Dentro de un trabajo de campo, inconcluso, estas dos historias particulares llaman la atención, pues sirven para mostrar estos modos de acción de naturaleza estratégica evocados antes. Pretenden descubrir, en primer lugar, los efectos que estos modos de hacer producen en la realidad fáctica de los practicantes entrevistados, pues evocan, en este sentido, esos procesos de interiorización-externalización creativa que ellas suponen al volcarse de una forma muy particular en la realidad. En segundo lugar, permiten teorizar -la primera historia específicamente- a propósito de las lógicas mítico-rituales que respaldan este tipo de práctica religiosa de matriz africana en Cuba. La segunda historia de vida no se privilegia en vano; tampoco constituye un paradigma en sí misma; sin embargo, se elige precisamente porque pondrá en la palestra una serie de conflictos sociales que han marcado la realidad cubana por un tiempo muy prolongado. 


\section{Ifalawo ${ }^{10}$, Patakin: operador mítico-simbólico}

La historia de E. está marcada por algunos eventos importantes. Uno de ellos viene aparejado a los 90, lapso eufemísticamente conocido en Cuba como especial: un largo periodo de crisis económica que comenzó como resultado del colapso de la Unión Soviética en 1991 y, por extensión, del CAME (Consejo de Ayuda Mutua Económica), así como por el recrudecimiento del bloqueo norteamericano impuesto a Cuba desde 1992. Una etapa que operó, producto de esta situación particular, serias repercusiones para la vida social insular, pues, al decir de Martin y Perera (1996), provocó una transformación radical en las formas habituales de la cotidianidad: estas se someten a complejos procesos de desestructuración y reestructuración de las representaciones, hábitos, expectativas, normas y actitudes ante la vida. Es precisamente en este periodo, de dureza económica e incertidumbre ante el futuro, que E. comienza a participar activamente en una de las tradiciones religiosas aquí evocadas, el segmento Ocha al interior del complejo religioso Ocha-Ifá. Este constituiría solo el primer peldaño que lo llevaría luego a erigirse como Sacerdote de Ifá o Babalawo un año más tarde. Este rito de paso significó, por su carácter jerárquico-ritual, una interiorización-externalización de las recomendaciones sumamente importante. Es precisamente aquí donde se articula otro de los cambios de mayor envergadura para la conducción de su vida, el giro que pone de manifiesto una historia biográfica problemática que venía ya advertida desde su entrada en la lógica de estos cultos. Uno de los puntos señalados en el día de Itá, cuenta E., fue precisamente lo referido a las formas que debían ser adoptadas a la hora de relacionarse con otros individuos, practicantes o no.

Estas recomendaciones ${ }^{11}$, que advirtieron principalmente sobre la traición y al desengaño como constantes al interior de su cotidianidad, vienen a determinar y a historiar, en el sentido particular de la práctica religiosa, vivencias ya padecidas; explicarlas si se quiere, darles nuevo sentido y justificación a la luz de la propia práctica, de su lógica y de las razones que de suyo ella procura para la realidad humana en su totalidad. Resulta interesante, sobre todo por el nivel de elaboración propia de un practicante con jerarquía ritual, la historia o patakin que viene a dar sentido y, en cierto modo, proyección a pautas de comportamientos muy particulares al interior de su vida cotidiana. Esto es lo que escucho de E.:

"... mira chico, uno de los patakin que me dijeron fue cuando Orunmila ${ }^{12}$ estaba trabajando para limpiar el mundo de injusticias y maldades y cosas malas que la

10 Título recibido por la jerarquía ritual que ostenta el practicante entrevistado. También es asumido como su nombre religioso. 11 Entre otras que interesarían en otro marco de análisis.

12 Orunmila es el oricha encargado de manejar el sistema de adivinación en el segmento Ifá. A esta figura mítica se le confirió un conocimiento extraordinario y el poder de anticipar los eventos: atributo que le permite conocer el principio y el fin de todo lo que existe. Él estaba junto a Olódumáré en el principio de la creación; sabe cómo se inició ésta y cómo se completó. Está presente cuando cada individuo es creado y cuando el destino de este es sellado. Por eso Orunmila puede predecir qué es lo que va a pasar y puede recomendar, a su vez y mediante Ifá que viene a ser un corpus filosófico-ritual, remedios o soluciones para modificar cualquier tipo de eventualidad. Sobre la base de estas afirmaciones el Babalawo sería una suerte de continuador del trabajo de Orunmila en el mundo. 
gente hacia... buscó ayuda en sus seguidores y amigos pero ellos en la noche salían y destruían todo su trabajo, el ayudaba a la gente con problemas... pero sus ayudantes salían en la noche y tiraban maldiciones, brujería y la gente se volvía a enfermar... a tener problemas... el mismo se consultó y descubrió que sus ayudantes eran los que causaban el desorden y le dijeron que tenía que sacrificar a $E c h u^{13}$ para poder realizar su trabajo y la mentira, la traición y el engaño pudiera descubrirse y así hizo y todo se descubrió... desde ese día pudo hacer su trabajo sin ser engañado... te imaginas que con estos truenos nadie duerme... por eso es que no me fio de nadie, la gente es muy oportunista y envidiosa, hasta mis hijos a veces me salen con cosas, mira yo he ayudado ... gente que ha venido en candela, les he dado cuando no han tenido para pagarse o las he puesto yo mismo las cosas y me han salido malos al final ..." (Entrevista realizada el 5 de setiembre de 2013).

Varias experiencias de vida inmerso en estas tramas interactivas, donde constantemente intervienen las diferentes figuras del otro en encuentros cara a cara -sean ahijados de la casa religiosa que preside este Babalawo o aquellos que en la vida cotidiana se entrecruzan emergiendo de forma única a cada momento- llaman a comentar sobre el tipo de acción puesto en marcha en este caso. De aquí la pregunta: ¿cómo opera E. en medio de una vida cifrada por este tipo de relaciones concretas - muchas veces conflictivas, pues envuelven, incluso, a miembros de su propia familia carnal o consanguínea- en su accionar cotidiano? Una vida cifrada por la traición y el desengaño apunta, por fuerza, hacia la adopción de estrategias que apuestan por escudriñar al otro de forma constante: incluso poner bajo la mirada que sospecha a miembros de su familia. Pareciera que asumir esta posición reflexiva, barnizada por cierto toque de escepticismo con el otro (tal como E. lo entiende y pone en práctica), es el modo de acción que encuentra como respuesta a estas recomendaciones dadas desde el proceso de envestidura como Babalawo hace aproximadamente diecisiete años. Sobre ello le escucho decir:

... a mi esta historia me sirve y no se me olvida, y me habla muy bien de todo el mundo a mi alrededor... por eso es que paso tiempo antes de dejar que alguien entre a mi casa religiosa... a que sean de aquí... ya los traidores y detractores de lo que hago se han ido saliendo... y así es mejor... (Entrevista realizada el 4 de octubre de 2013. Aquí refiere a su casa religiosa).

Si bien la atención se deposita en los modos de acción, en esas mil mañas que permiten al practicante hacerse de un espacio propio y desde ahí acometer acciones emancipadoras de una realidad vivida, o sea, asumir como tarea la constante subversión de una experiencia cotidiana marcada por estos tipos de interacciones, se cree oportuno reflexionar sobre el artefacto que lo habilita, vale decir, la historia mítica o patakin. El alcance operativo del patakin, en esta lógica, no debe reducirse al mero hecho que describe.

13 Oricha encargado de equilibrar dinámicamente el mundo y controlar los Ajogún: fuerzas malignas de un mundo bipolar.

Cuadernos de Antropología 2014, 24(1), 3-20 
No puede interpretarse en un único sentido - solo los seguidores son los que desestabilizan el accionar de este oricha revirtiendo los efectos reparadores que logra o su capacidad resolutiva ante problemáticas de "cualquier" tipo-, sino a la franca homologación que E. pone en perspectiva con respecto a los personajes que intervienen con lo que sería la heterogeneidad de individuos (practicantes o no) que traban relación con él ${ }^{14}$ en su espacio tanto público como privado. De ello se derivada la aplicación práctica o utilización estratégica de este patakin a su biografía personal, aplicación que en su caso deviene esencial para la estructuración y pilotaje de su vida.

Se asiste, en este caso, a lo que en principio se definía como un tipo de estrategia: la polivalencia o, más bien, a lo que podría denominarse, en este caso, una forma particular de polivalencia. El patakin tiene empleos múltiples, extracircunstanciales y extrapersonales, se hace extensivo y, por tanto, inclusivo de todas y todos, pues su alcance sobrepasa los simples enunciados que nombra e implica en su puesta en práctica, no solo el espacio y el tiempo de la acción propiamente dicha, sino una rutinización de la propia acción. La lógica de la historia y su aplicabilidad continua (la rutinización) pretenden otorgar a su vida cotidiana, el sentimiento de confianza y seguridad necesario para su desarrollo. En este sentido, viene a significar el poder de subvertir y emanciparse de un tipo de relación problemática y asidua en su biografía personal. En esta línea de pensamiento, el patakin puede ser considerado como un operador mítico-simbólico en tanto promueve un accionar cuya lógica y fundamento último se encuentran localizados al interior de una narración de igual naturaleza (mítica-simbólica); un dispositivo capaz de orientar, determinar, interceptar, modelar, controlar y asegurar los gestos, las conductas, las opiniones y los discursos de practicante. Esto engarza con una postura que piensa "la religión" como un artefacto de reencuadre estratégico, emancipador ante determinadas coyunturas ligadas a la existencia. Asimismo, como otro código cultural de naturaleza simbólica capaz de construir sentido, un artefacto que permite al practicante transformarse con el fin de lograr ciertos estados de espiritualidad o armonía (Mancini, 2008) y, al mismo tiempo, operar ciertos cambios, reestructuraciones o reacomodos en su accionar cotidiano, sus comportamientos, las conductas en relación con el entorno social, político, económico, cultural en donde se desenvuelve ${ }^{15}$.

\section{Obiní, (con)vivencias...}

Escuchar a M. es asistir quizás a la historia de muchas mujeres cubanas. Es percibir el eco resonante de una cultura marcadamente patriarcal de corte verticalista que asume de suyo la violencia contra la mujer como algo natural; una experiencia que luego es traducida en estereotipos que marcan un posicionamiento muy generalizado en una sociedad históricamente prejuiciada y discriminatoria con respecto al "negro". Estas son las primeras notas que pueden hacerse a propósito de la historia de vida de M. Una

14 En este caso E. encarna la figura del oricha.

$15 \mathrm{La}$ idea de concebir las religiones como artefactos o dispositivos se inspira en los trabajos realizados por investigadores como Silvia Mancini (2008) y Michel Foucault (1990).

http://revistas.ucr.ac.cr/index.php/antropologia 
mujer que ha arribado a sus 34 años; una profesional de la salud marcada por los conflictos cotidianos de un periodo difícil donde las configuraciones de la vida, atravesadas principalmente por necesidades básicas de subsistencia, no responden a certidumbres, sino a esa ansiedad repetida que asocia lo desconocido con lo previsible e incierto del acontecimiento diario. Profesional, ama de casa, dualidad nada extraña a la condición histórica de la mujer en nuestra realidad insular; sujeta a violencia de genero durante los últimos diez años de su vida y por ello divorciada, con dos hijos adolescentes de trece y catorce años de edad cada uno y en plena formación. M. afronta su vida con la mayor temeridad posible y necesaria dada su particular condición existencial. Lejos de sentirse una mujer desvalida producto de su inestabilidad económica y emocional, principalmente, y frente a los múltiples fracasos en este último ámbito de relaciones, se siente fortalecida por una tradición religiosa que su familia ha mantenido por tres generaciones y cuyos vínculos y actividades relacionadas íntimamente con lo sobrenatural (los orichas) se mantienen hoy más fuertes que nunca. Para M., recurrir a estas prácticas, no sin antes asumir su tradición familiar de la cual renegaba decididamente y asentar su oricha tutelar: Yemaya en su camino Ibu Tinibu, vino a ser la solución eficaz que apostó por subvertir las condiciones que desde un tiempo importante de su vida venía padeciendo. Este aspecto se le presenta a M., desde su propia sentir, como fundante para lo que ha sido la resolución de muchas de las problemáticas que han afectado su vida, tanto material como espiritual.

Del amplio espectro en materia de recomendaciones, una en particular, de mano del caracol de $Y e$ maya, es de sumo interés, pues ésta, articulada conjuntamente con su experiencia personal, refunda una relación con el mundo y con las figuras del otro un tanto particular. Una recomendación que propicia, para la propia practicante, un giro no casual o arbitrario en su vida, pues se ocupa de su salud físico-emocional. Se trata de la selección minuciosa de sus parejas bajo criterios bien estrictos de no violencia o, lo que es lo mismo, seleccionar parejas que no sean propensas a la violencia. Si se traduce en los términos manejados en este espacio, se trataría de la búsqueda de coyunturas emancipadoras o subvertidoras de lo que ha marcado su vida emocional y, en cierto modo, social. El modus operandi o la operacionalización estratégica de esta recomendación, entonces, se efectúa bajo condiciones que excluyen al "negro y al mulato" de sus marcos relacionales más estrechos (relaciones de pareja), dadas sus propensiones, según expresa M., hacia la violencia y la ingestión desmedidas de bebidas alcohólicas (esto último, al sentir de M., es el detonante o catalizador que propicia este tipo de comportamientos). El siguiente relato de su vida, que para nada tiene que ver con lo religioso, muestra la percepción de M. en lo referente a las "razas" y al mismo tiempo, coloca al lector en sintonía con el trasfondo experiencial de la entrevistada y su accionar :

... los negros [comenta M.], cuando están con una blanca creen que pueden hacer lo que quiera, se creen dueños de una" [Y agrega] "mira... yo he pasado mi vida con negros y mulatos, los padres de mis hijos son negros, me gustan, pero he tenido que separarme de ellos porque no soportaba más, ya no podía manejar las situaciones en mi casa, con mi madre ahí y mis hijos ... y mi mamá me lo advirtió muchas veces ... tiene que ser algo de los negros o mucha mala suerte mía... a mí ya no me pasa más eso, ya yo me cansé ... (Entrevista realizada el 22 de julio y 26 de agosto de 2013).

Cuadernos de Antropología 2014, 24(1), 3-20 
Desde estos sentires particulares es pertinente observar cómo su accionar se inscribe en esto que se ha catalogado antes como lugar propio, un espacio donde la voluntad de cambio necesario, combinada con vivencias personales -aunque sin separarse de lo que se ha denominado control ritual, sino adscribiendo su accionar a cierta forma de disciplina religiosa- permiten a M. relacionarse de forma simétrica con ese otro que aquí adopta la forma de "las parejas". Si se toma como referente lo enunciado al principio, este modo de hacer (de naturaleza estratégica) pone en perspectiva manejos combinatorios que sugieren esa economía de esfuerzos que cifra en una sola acción, sus vivencias personales, la cuestión normativa de sus relaciones bajo los términos que propone esta recomendación y las relaciones de pareja que desde aquí puedan o tienen lugar. Esta forma de hacer sugiere, entonces, la equivocada homologación entre "parejas violentas" y "hombres negros o mulatos". Asume desde una vivencia personal que el "hombre negro o mulato" es violento; y es precisamente a partir de esta percepción específica o desde un tipo de racionalidad muy particular que la recomendación es seguida por la practicante. Sin dudas se está frente al desborde de los límites de la recomendación ritual y de la práctica religiosa que para nada transita por las lógicas de la discriminación racial. Resulta interesante observar, no obstante, como M. logra situar esta recomendación - muy personal- en un espacio que logra desvirtuar su especificidad; es decir, la recomendación es sobredimensionada y reajustada a sus experiencias personales, experiencias que han trastocado su sentido primero hasta expulsarla del ámbito de lo religioso solo para ser vector de sus vivencias pasadas.

Vale apuntar que más allá de estas vivencias (que no pueden ser desdeñadas), de sus juicios instalados (internalizados a raíz de su propia experiencia de vida) y la evidente proyección de estos en las formas de ordenar su realidad (o lo que sería la externalización de estos juicios bajo la lógica de las recomendaciones en su práctica cotidiana), se está en presencia de un mecanismo muy sutil que reproduce los prejuicios raciales que históricamente han marcado la vida del "negro" y el "mulato" en Cuba. La historia de M., sin lugar a dudas, nos habla de uno de los conflictos más arraigados, uno de tantos, en la sociedad cubana. Si bien la intención política y sociocultural de la revolución socialista fue desde su inicio antirracista, por ende, inclusiva de todas y todos y promovió, en este sentido, igualdad de derechos, el imaginario sobre el "negro" y el "mestizo" en general, en tanto individuo marginal, violento, bárbaro, etc. siguió reproduciéndose en los entramados, más secretos, de la población cubana. Contradictorio al proceso revolucionario y a sus pretensiones altamente dinámicas en materia de reformas sociales "inclusivas" - es bien conocido que no funcionó de esta forma para todos los sectores de la población (religiosos, homosexuales, hippies, etc. no fueron incluidos)-, los prejuicios raciales y su correlato conductual, la discriminación racial, es un hecho que aun hoy, a pocos años de comienzo del S. XXI, se da desde una intersubjetividad y subjetividad que no ha sido emancipada de los prejuicios raciales que históricamente han marcada la sociedad cubana.

Se trata, más allá de la intencionalidad política, de una cuestión netamente individual que escapa al control de estrategias oficiales y que tiene sus raíces, muchas veces, en el núcleo básico de la sociedad cubana: la familia. Esta última, desempeña un papel importante en la reproducción o no de los prejuicios y estereotipos raciales y sus concomitantes conductas discriminatorias, por su carácter socializador y endoculturador. En este sentido, si no ocupa el lugar preponderante, la familia constituye la piedra angular 
para emprender cualquier acción al respecto. En la explícita reproducción de los prejuicios raciales desde el interior de la familia de M.: “...mi madre me lo advirtió muchas veces...”, se encuentran los elementos que permiten pensar las intersubjetividades a escala microsocial y, conjuntamente a ello, la consolidación de un tipo social que estigmatiza a este sector de la población, convirtiéndolo en un producto humano estereotipado, una suerte de "lacra irredimible". Un criterio que de forma explícita sugiere una postura que imposibilita modelar nuevas acciones que favorezcan la erradicación de tales prejuicios. Si bien este hecho (la discriminación racial) no puede hacerse extensible a toda la sociedad, tampoco puede obviarse al punto de enunciar su superación, elemento importante a acotar, pues ello solo conduciría a disfrazar una de las tantas problemáticas que aún subsisten en una sociedad en riesgo como la cubana.

\section{Consideraciones finales}

Desde una panorámica general, este artículo pretendió asumir una postura que permitiera inscribir en la vida cotidiana una realidad religiosa compleja y evasiva por naturaleza; ello desde una antropología que apostó por privilegiar el estudio de los saberes aplicados a la vida, las estrategias en tanto prácticas que se presentan como resistencia ante determinadas catástrofes biográficas. Se trató en este sentido de explicitar los usos instrumentales de las recomendaciones a partir de entender, más allá de la subjetividad intrínseca de la que son producto, las racionalidades utilizadas por los practicantes en aras de subvertir determinadas coyunturas existenciales. Este espacio no solo se presentó como un intento por exhumar modelos de acción estratégicos e individuales, descifrar cómo los ejes sociales, determinadas coyunturas culturales, la "disciplina religiosa" exigida por la iniciación ritual, ejercen presión sobre estos modelos, sino también por observar al par, las combinaciones operatorias que los practicantes ponen en juego para acomodar incesantemente las relaciones de fuerza existentes entre una realidad social cambiante, compleja y las recomendaciones emanadas de la iniciación ritual.

Estas combinaciones de tipo emancipatorias y susceptibles de ser observadas desde su dimensión de resistencia no son en sí mismas inocentes. Se tornan una espiral que recae o vuelve sobre problemáticas bien complejas aún por resolver. Si bien emanciparse de tramas relacionales que incluyen la traición o la violencia doméstica es una opción necesaria e impostergable porque solo así se puede ganar un espacio de convivencia digna, humana, las formas de hacerlo: la mirada que sospecha de todas y todos o los prejuicios raciales que se reproducen; por ejemplo, son reflejo de problemáticas mayores que no dejan de cuestionar las lógicas que dinamizan la vida social cubana actual y que exigen un nuevo acercamiento. Sin dudas, estas historias de vida, específicamente la última, ponen en la palestra una problemática que necesita nuevos ejes de análisis. En este sentido, urge la necesidad de una nueva aproximación que permita descolocar la mirada y poner en tela de juicio esas estructuras históricas de segregación o de prejuicios con respecto al negro que aún hoy asisten a cubanas y cubanos: sería observar minuciosamente desde aquí las formas que adopta, formas muy sutiles por momentos, la discriminación racial para poder hacerlas visibles, detectarlas con miras a transformarlas. De igual forma, se presenta como imperativo observar esta última historia de vida a la luz

Cuadernos de Antropología 2014, 24(1), 3-20 
de los estudios de género, las teorías feministas para poder dilucidar la complejidad de una experiencia de vida que no duda en repetirse en las historias de otras mujeres oprimidas. En este sentido, los cruzamientos entre un patriarcado histórico, prejuicios raciales y discriminación por género son ejes de análisis que bien pueden modelar respuestas emancipatorias no solo para la practicante en cuestión, sino para otras tantas mujeres que transitan por lógicas patriarcales similares, donde la mujer se ve sumida en relaciones de poder desiguales, donde la equidad, por momentos, es solo sueño.

Se trata también, vuelvo sobre una idea apuntada más arriba, de observar esto que Occidente ha denominado "religión", bajo una mirada que insiste en privilegiar su eficacia técnica en tanto proporciona al individuo instrumentos, más allá de sus usos, que posibilitan el manejo de la vida haciendo de esta misma zonas de resistencia y cambio ante eventualidades de cualquier tipo. Es observar los efectos que "la religión" tiene sobre la realidad tal cual es percibida y experimentada por los practicantes, observar su efecto muchas veces emancipador y, por tanto, subvertidor de las estructuras de poder en las que se encuentran enclaustrados. Los análisis aquí efectuados, quizá poco minuciosos a la mirada especializada, no pueden tomarse como resultados acabados, sino como parte de los avances de un estudio en curso. Un estudio que pretende interrogar otras prácticas cotidianas: comer determinados alimentos, vestir o utilizar determinadas ropas y aditamentos. En este sentido, analizar las estrategias que son puestas en marcha por los practicantes para lograr acomodar coyunturas económicas, sociales, culturales específicas y las recomendaciones proporcionadas una vez que se inician en la práctica religiosa aquí abordada. De aquí que este espacio solo represente un primer corte que muestra lo que de facto es conocimiento general: la complejidad de la vida humana y los medios que encuentra para gestionarse a sí misma. En el caso que ocupa, mediante prácticas religiosas que apuntalan la existencia individual frente a determinadas desestructuraciones de la cotidianidad.

\section{Referencias bibliográficas}

Aboy, N. (2004). El código ético e identitario en La Regla de Ocha en 25 Siglos de Historia de la Santería Cubana. Santander: Exa. Editores. S. A.

Berger, P. L y Luckmann, T. (2011). La construcción social de la realidad (1 ${ }^{\text {ra }}$ ed., $22^{\text {da }}$ reimp.). Buenos Aires: Amorrortu.

Bourdieu, P. (2007). Estructura, habitus, prácticas, en el sentido práctico. Buenos Aires: Siglo XXI Editores.

De Certeau, M. (2000). La invención de lo cotidiano, I Artes de hacer. México: Universidad Iberoamericana.

De Souza, A. (2005). Los orichas en África: una aproximación a nuestra identidad. La Habana: Ciencias Sociales. 
De Souza, A. (2010). Ifá. Santa palabra, Concepto ético sobre el carácter y la ancianidad. La Habana: Ediciones Unión.

Foucault. M. (1990). Tecnologías del yo y otros textos afines. Barcelona: Ediciones Paidós Ibérica, S.A.

Foucault. M. (2005). La hermenéutica del sujeto. Madrid: Ediciones Akal.

Giddens, A. (2006). La constitución de la sociedad: bases para la teoría de la estructuración $\left(1^{\text {ra }}\right.$ ed. $3^{\text {ra }}$ reimp.). Buenos Aires: Amorrortu.

González, F. y Villegas, M. (2009). Fundamentos epistemológicos en la construcción de una metódica de investigación. En: Atos de Pesquisa em Educação, (4)1, 89-121.

Hernández, F. (2009). ¿Crisis de valores en Cuba?. Recuperado el 5 de mayo de 2014, de http://www. archivocubano.org/storia/crisis_valores.html.

Lefébvre, H. (1978). Introducción a la psicosociología de la vida cotidiana. En H. Lefébvre, De rural a lo urbano (4 ${ }^{\text {ta }}$ Ed.) (pp. 86-90). Barcelona: Península.

Martin, A. V. (1995). Fundamentación teórica y uso de las historias de vida y relatos de vida como técnicas de investigación en pedagogía social. Aula, 7, 41-60.

Martin, C. y Perera, M. (1996). La vida cotidiana en Cuba. Una mirada psicosocial. Revista Temas, 92-98.

Mancini, S. (2008). Saberes técnicos y ortoprácticas rituales en el cruce de las ciencias humanas y las ciencias de la vida, en La Fabricación del psiquismo. Buenos Aires: Libros de Araucaria.

Menéndez, L. (1995). ¡¿Un cake para Obatala!?. Revista Temas (3ra época), 4.

Menéndez, L. (1998). Estudios afro-cubanos. La Habana: Facultad de Artes y Letras, Universidad de La Habana.

Menéndez, L. (2002). Rodar el coco. Procesos de cambio en la santería. La Habana: Fundación Fernando Ortiz.

Sorín, M. (1989): Cultura y vida cotidiana. Revista Casa, 178. 
